\title{
THE DISPOSITION AND EXTERNAL MORPHOLOGY OF TRICHOBOTHRIA IN TWO ARACHNIDS
}

\author{
Geethabali and Sulochana D. Moro \\ Neurophysiology Laboratory, Department of Zoology, \\ Bangalore University, Bangalore--560056, India
}

\begin{abstract}
Synopsis
Geethabali and Sulochana D. Moro (Neurophysiology Laboratory, Department of Zoology, Bangalore University, Bangalore-560056, India): The disposition and external morphology of trichobothria in two arachnids. Acta arachnol., 36 : 11-23 (1988).

The distribution and external morphology of trichobothria in the whip scorpion, Thelyphonus indicus, and the scorpion, Heterometrus fulvipes, have been studied. While the whip scorpion has its trichobothria remarkably reduced in number to just 10 distributed on the tibiae of the legs, the scorpion has totally 96 trichobothria with 48 on each pedipalp. The sockets as well as hair shafts of the trichobothria on the antenniform legs of the whip scorpion differ widely in their appearance from those on the walking legs. The trichobothria of the scorpion resemble those on the antenniform legs of the whip scorpion, but differ due to the lamellated wall of the cup of the trichobothrium in the scorpion. The directions of mobilities of individual trichobothria in both the arachnids have also been mapped.
\end{abstract}

\section{Introduction}

The trichobothria of arachnids are very fine hair sensilla remarkably sensitive to air currents, articulated within and emerging from independent sockets in the cuticle. They were first discovered on the extremities in Araneae by DAHL (1883) who called them 'Hörhaare' (hairs of hearing). The sensitivity of trichobothria to air currents was demonstrated in a scorpion (HoFFMAN, 1967) and a spider (GöRnER \& ANDREWS, 1969).

Since the number and arrangement of trichobothria remain constant within individuals of a species but vary from species to species, trichobothrial patterns are used in systematics and classification and in the study of development (WEY- 
GOLDT, 1970; GabBUT, 1972 ; GabBuT \& VACHON, 1965; EMERIT \& BonaRIC, 1975 ; etc.).

In spiders, trichobothria are numerous and are found on the pedipalps and walking legs. Each leg bears 25 trichobothria in Agelena labyrinthica C. (GöRNER \& ANDREWS, 1969) and 50 in Cupiennius salei Keys. (BARTH, 1982). The properties of trichobothria in spiders have been studied by GörNER (1965), GöRNER \& Andrews (1969), Christian (1971, 1972), Harris \& Mill (1977), Reißland (1978) and REIßLAND \& GÖRNER (1978).

In scorpions, trichobothria are found exclusively on the pedipalps. In various species of Euscorpius, each pedipalp bears from 60 to 88 trichobothria (HoFfmAN, 1967). The properties of trichobothria in scorpions have been studied by HoFFMAN (1967) and IGNATJEv et al. (1976).

Other than a mention of the presence of 10 trichobothria on the legs of the whip scorpion, Typopeltis stimpsonii Wood (YosHIKURA, 1965), no further attempt has been made to study the trichobothria of whip scorpions. We have therefore studied the trichobothria in the whip scorpion, Thelyphonus indicus, with respect to their distribution and external morphological details in comparison with similar observations made in the scorpion, Heterometrus fulvipes, which occurs in the same habitat. This study would facilitate further physiological studies on the trichobothria and their role in the behaviour of these species.

\section{Materials and Methods}

Fresh specimens of the whip scorpion, Thelyphonus indicus STOLICZKA, and of the scorpion, Heterometrus fulvipes C. L. KocH, were examined under a stereo light microscope for the position and distribution of trichobothria. The lengths and diameters of the trichobothria were measured using a calibrated ocular grid. The directions of mobilities of individual trichobothria were examined under the microscope by subjecting the trichobothria to air puffs from different directions and noting the directions in which a particular trichobothrium moved with respect to the long axis of the appendage. For scanning under an electron microscope (Cambridge Stereoscan 150), the part of the appendage bearing trichobothria was cleaned and dehydrated in a mixture of chloroform and methanol $(2: 1)$ and coated with gold before mounting for observation. 


\section{Results}

\section{A. Trichobothria in Thelyphonus indicus:}

It is very interesting that the whip scorpion has only 10 trichobothria which are confined to its legs. The first legs have two trichobothria each while the walking legs have one each (Fig. 1). The trichobothria on the first pair of antenniform legs differ in their position and external morphology from those on the walking legs, hence they have been described separately below.

\section{Trichobothria on the first legs}

The two trichobothria on each of the first legs are situated close together at the distal end of the tibia on its dorsal surface. They are placed diagonally $0.22 \mu \mathrm{m}$ away from each other, one being closer to the tibio-tarsal joint than the other which is approximately on the mid-dorsal line of the tibia (Fig. 1a). The length of each trichobothrium ranges from $1.7 \mathrm{~mm}$ to $2.2 \mathrm{~mm}$ in different animals. The diameter of the base of the hair shaft is about $10.2 \mu \mathrm{m}$ and the

a

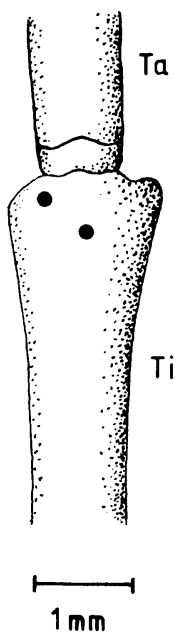

b

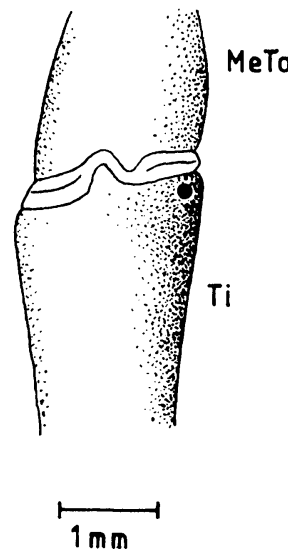

Fig. 1. Diagrammatic representation of the position of trichobothria (0) on the tibia (Ti) of: (a) First leg and (b) Walking leg of whip scorpion. Ta $=$ tarsus, $\mathrm{MeTa}=$ metatarsus. 


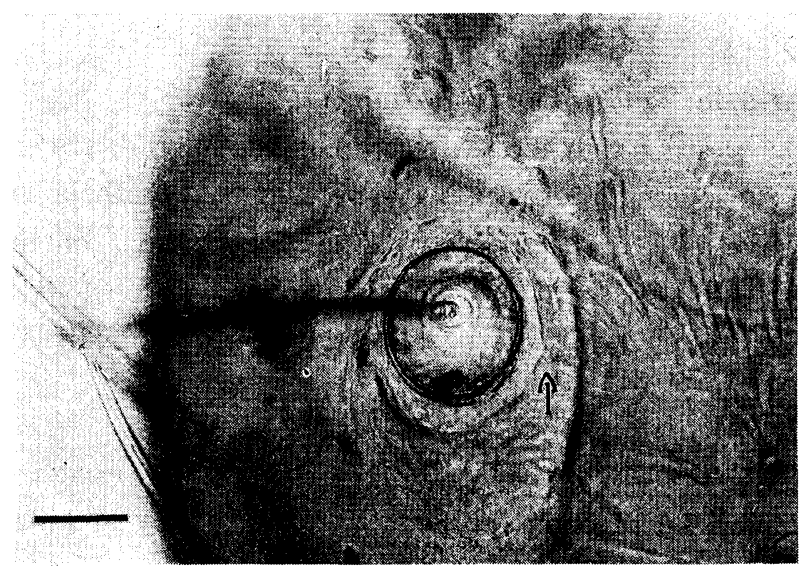

Fig. 2. Transmission light microscopic picture of the socket of the trichobothrium on the first leg of whip scorpion showing the eccentric position of the hair in the cup. Arrow shows the depression in the cuticle in which the socket is placed and also points towards the distal end of the tibia. Scale $=200 \mu \mathrm{m}$.

socket diameter is roughly $30 \mu \mathrm{m}$. Each of the two sockets is a clear pit-like depression which is in turn placed in an asymmetrical depression on the cuticular surface (Fig. 2). The trichobothrial hair shafts are eccentrically placed within their sockets. The hair shafts of the two trichobothria, after emergence from their respective sockets, diverge away from each other, being relatively straight compared to the trichobothria on the walking legs.

\section{Trichobothria on the walking legs}

Each of the six walking legs bears a single long trichobothrium at the distal end of the tibia on its postero-dorsal margin and close to the tibio-metatarsal joint (Fig. 1b). The trichobothrium on the walking leg measures about $2.3 \mathrm{~mm}$ in length with the hair shaft having a diameter of $12 \mu \mathrm{m}$ at its base. The hair shaft is eccentrically placed within its socket, which measures about $70 \mu \mathrm{m}$ in diameter. The socket of the trichobothrium of a walking leg is an elevated dome-shaped structure similar to that in spider in contrast to that of the first leg which is an open cup-like depression similar to that in scorpion (Fig. 3). One of the most interesting features of the trichobothrium on the walking leg is tis peculiar nature of curling up roughly in the shape of a question mark (Fig. 4). The hair, however, loses this characteristic shape in the presence of 

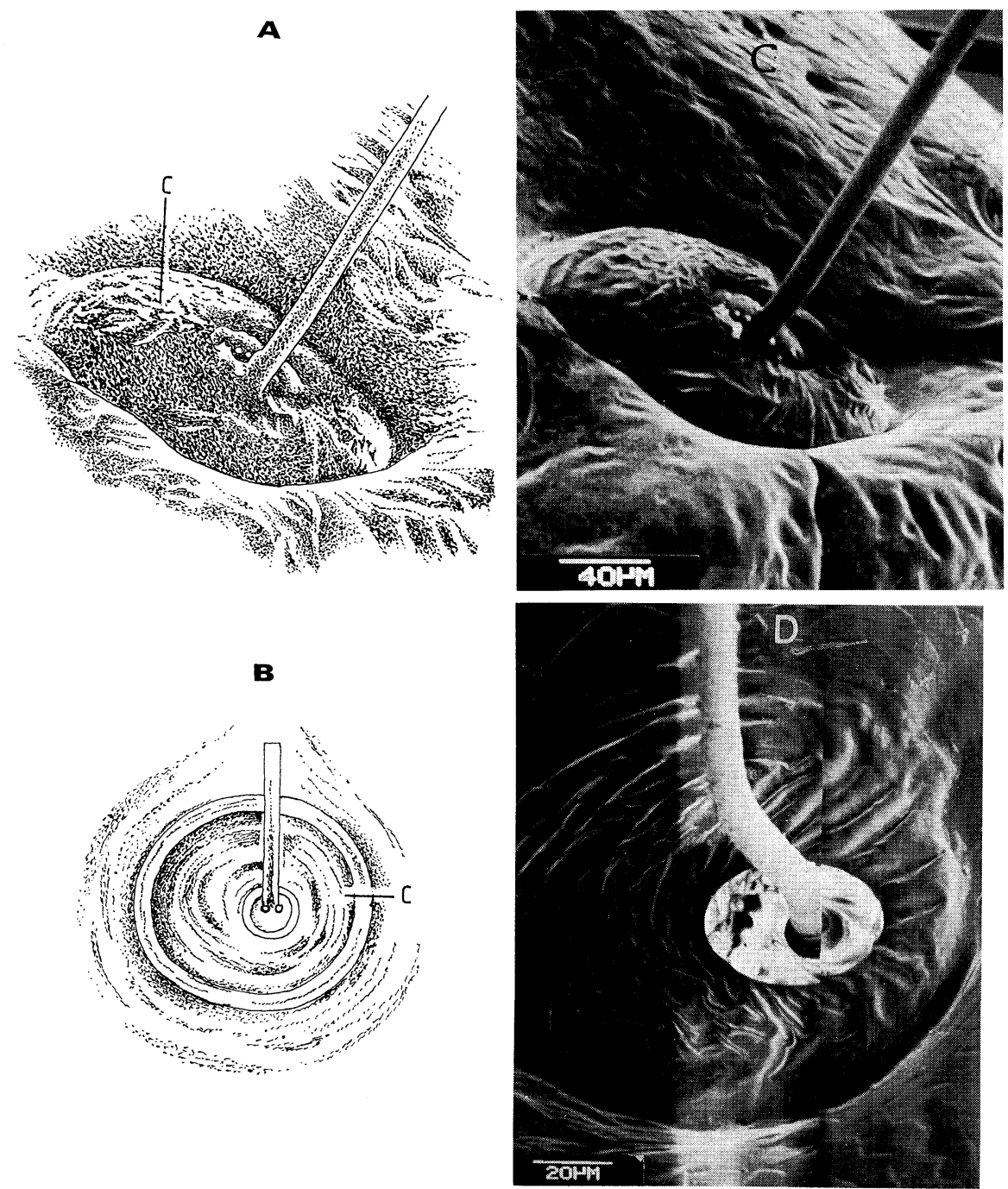

Fig. 3. Differences in the trichobothrial sockets (c) on: (A) The walking leg and (B) the first leg of the whip scorpion which resemble those found on the leg of spider (GörNer, 1965) and the pedipalp of scorpion (HofFMAN, 1967), respectively. (C) and (D) are scanning electronmicrographs of (A) and (B), respectively. 


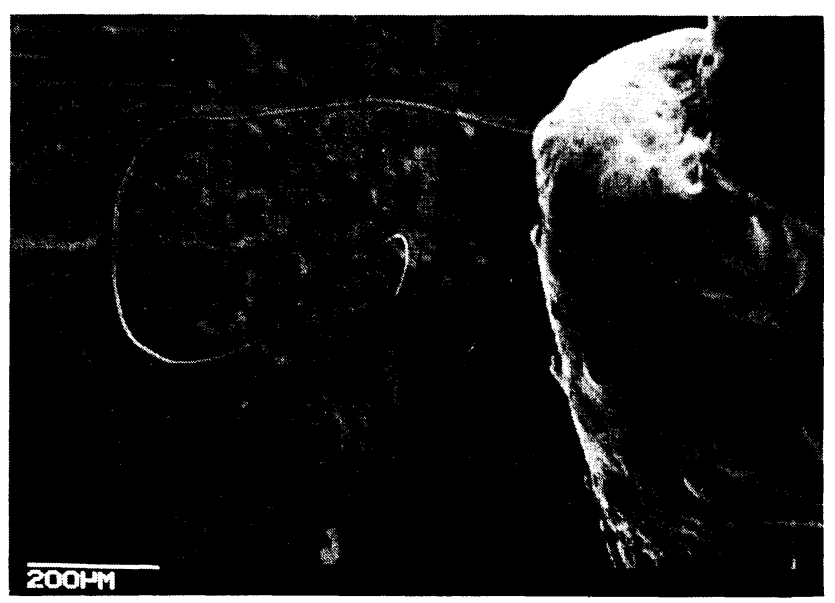

Fig. 4. Scanning electronmicrograph of the trichobothrial hair shaft on the walking leg of whip scorpion, showing its curled nature.

water but curls back to its original shape when dry.

\section{Mobilities of the trichobothria}

Each of the ten trichobothria has its own fixed plane of movement irrespective of the direction of air current delivered to it. Figure 5 shows the direction of mobility of each of the 10 trichobothria. The directions of mobilities of the two trichobothria on the first leg are at right angles to one another and at $45^{\circ}$ to the long axis of the leg. The direction of mobility of the trichobothrium on a walking leg is also at $45^{\circ}$ to the long axis of the leg. However, in its normal posture, the whip scorpion has its legs spread out in different directions with each of the tibiae oriented in a different direction around the animal's center, thus forming a circle. Consequently, the trichobothria are also placed roughly in a circle around the animal's centre. Thus, the directions in which the trichobothria oscillate preferentially cover roughly $360^{\circ}$ around the centre of the animal.

\section{B. Trichobothria in Heterometrus fulvipes:}

In this case, trichobothria are found exclusively on the pedipalps. Each pedipalp bears 48 trichobothria similarly distributed on the left and right pedipalp. Figure 6 shows the distribution of trichobothria on the left pedipalp. The maximum number of trichobothria are seen on the dorsal surface of the 


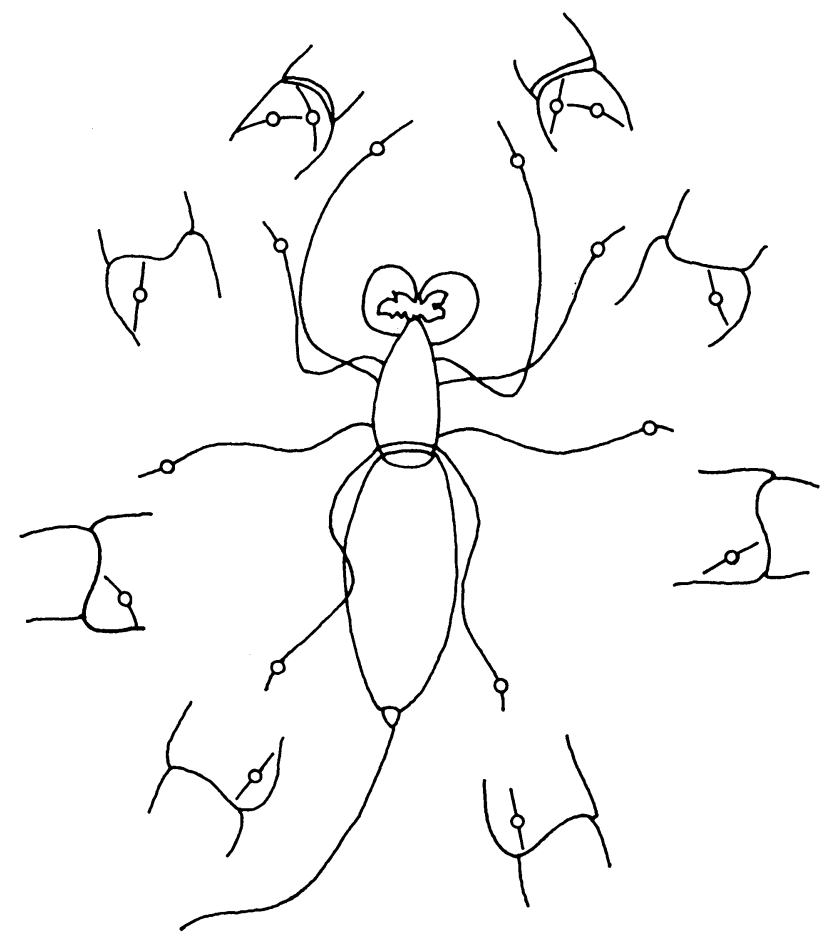

Fig. 5. The direction of mobility of each of the trichobothria on the legs of the whip scorpion in one of its natural postures. Location of trichobothria on the respective tibiae marked by $\bigcirc$. A part of each of the tibiae is enlarged to show the directions of mobilities clearly.

pedipalp while the ventral view shows the least. Table 1 shows the lengths of the trichobothria on different segments of the pedipalp. The lengths of the trichobothria in an adult scorpion range from 570 to $1800 \mu \mathrm{m}$.

Each trichobothrium arises from an independent radially symmetrical cup measuring roughly $70 \mu \mathrm{m}$ in diameter. The hair shaft measures about $12 \mu \mathrm{m}$ in diameter at its base and is eccentrically placed within its cup. After emergence the hair shafts stand erect at about $90^{\circ}$ to the surface of the pedipalp (Fig. 7a). The hair shaft of the trichobothrium has a smooth surface throughout.

The socket of the trichobothrium, which is a clear cup-like depression, does not have a smooth inner wall which, however, has a brick-like arrangement of 


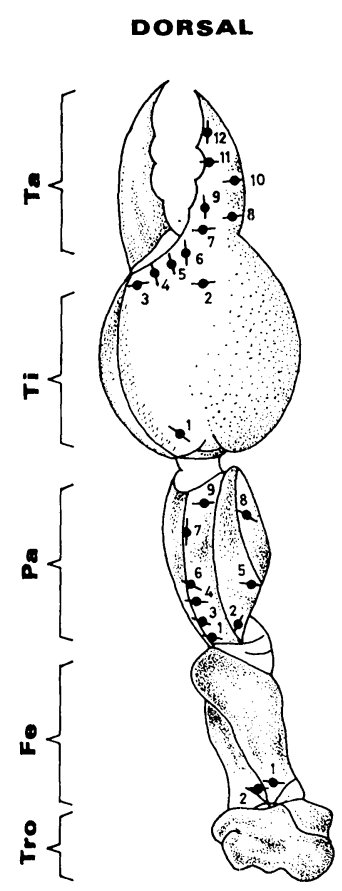

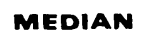

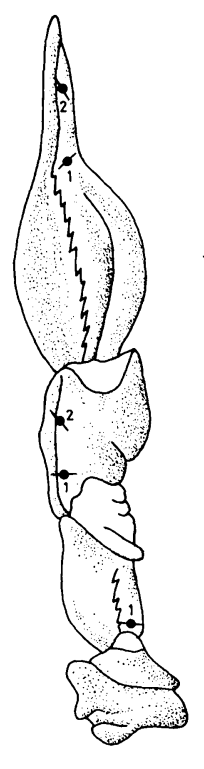

VENTRAL

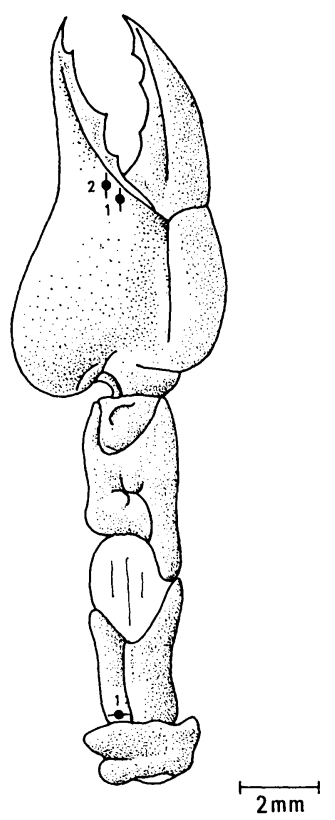

LATERAL

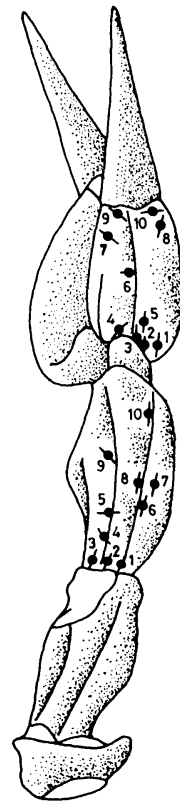

Fig. 6. Map of the trichobothria (๑) along with their individual directions of preferential movements (--) on the left pedipalp of the scorpion. The trichobothria on the different segments have been indexed following HofFmaN (1967). $\mathrm{Tr}=$ trochanter, $\mathrm{Fe}=$ femur, $\mathrm{Pa}=$ patella, $\mathrm{Ti}=$ tibia and $\mathrm{Ta}=$ tarsus.

Table 1. The number and distribution of trichobothria on the various aspects of the segments of the pedipalp of the scorpion, Heterometrus fulvipes. Those marked with * are common to both the surfaces of the segment between which the number is placed.

\begin{tabular}{|c|c|c|c|c|c|}
\hline & & DORSAL & MEDIAN & VENTRAL & LATERAL \\
\hline \multirow{2}{*}{ TIBIA } & No. of Trichobothria & 12 & 2 & 2 & 10 \\
\hline & Length (mm) & $0.57-1.46$ & $1.11-1.16$ & 1.34 & $0.69-1.46$ \\
\hline \multirow{2}{*}{ PATELLA } & No. of Trichobothria & 7 & $2^{*}$ & - & 10 \\
\hline & Length $(\mathrm{mm})$ & 0.57 & $7-1.53$ & - & $0.57-1.80$ \\
\hline \multirow{3}{*}{ FEMUR } & No. of Trichobothria & 2 & & $1^{*}$ & - \\
\hline & Length $(\mathrm{mm})$ & $0.84-1.23$ & & 0.92 & \\
\hline & $\begin{array}{l}\text { Total No. of } \\
\text { Trichobothria }\end{array}$ & 21 & $2^{*}$ & $1^{*}$ & 20 \\
\hline
\end{tabular}



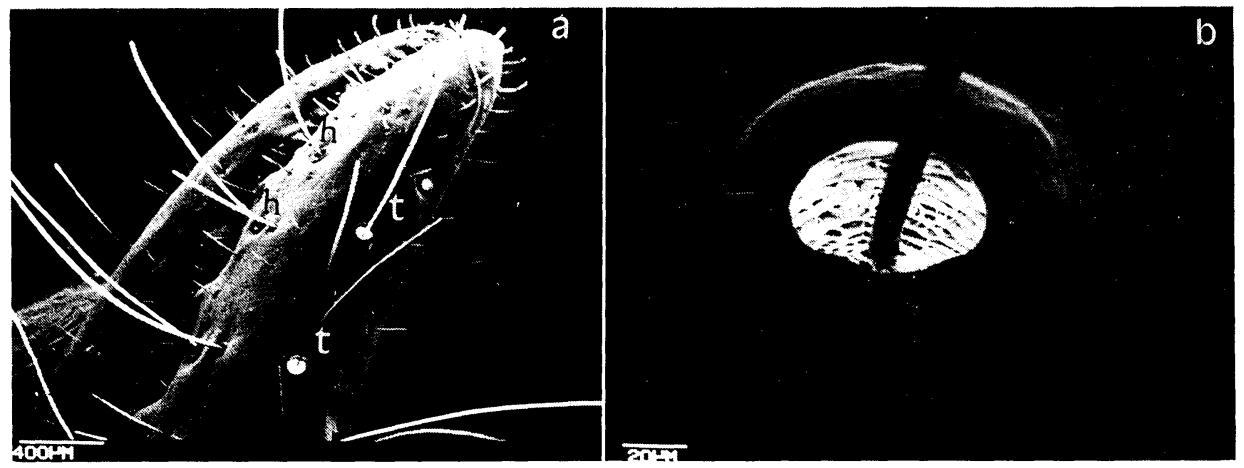

Fig. 7. Scanning electron micrographs of (a) The distal end of the tibia of the pedipalp of scorpion in its dorsal view showing trichobothria $(t)$ as well as other hairs (h). (b) The base of one of the trichobothria revealing the lamellated inner wall of the cup.

its cuticular lamellae, giving a spongy appearance, as seen in Figure 7b.

The directions of mobilities of the individual trichobothria are indicated in Figure 6. Each trichobothriumw as found to have its own fixed plane of movement irrespective of the direction of the air current impinging on it. In cases where trichobothria are placed parallel to each other they were found to exhibit the same direction of mobility.

\section{Discussion}

In the whip scorpion, the number and external morphology of trichobothria on the first leg are different from that on the walking leg. The first leg is more flexible and can move about in various directions. Hence, it is quite plausible that there are two trichobothria on the first leg with their planes of movements at right angles to each other which would help in the perception of air currents from a wide range of directions around the animal's center depending on the position of the first leg. The differences in the shape of the socket and of the hair shaft between trichobothria on the first legs and the walking legs also indicates the possibility of differences in their functional properties. Hence, the whip scorpion forms a very interesting material for studying the functional properties of trichobothria in greater depth.

While the inner wall of the cup of the trichobothrium has a smooth, continuous surface in case of the first leg of whip scorpion, the inner wall in case 
of the scorpion is not continuous but appears cut giving a spongy appearance. This appears to be due to the cup being made up of chitin lamellae arranged one above the other over its inner wall as also observed by HoFFMAN (1967) in the scorpion, Euscorpius.

In the whip scorpion, the trichobothrium of the walking leg is relatively long but has a peculiar curled nature of its hair shaft unlike those on the first leg. Such long hairs may be disadvantageous for mechanical reasons since very long hairs are known to have high stimulus threshold as discussed by TAUTZ (1979). The curling up of the hair shaft may help by increasing the effectiveness of the stimulus since such a hair can be more readily deflected by air currents than an elongated hair of equivalent length.

While the trichobothria of spider were found to be isotropic in their movements (GöRNER \& ANDREWS, 1969), each trichobothrium of the whip scorpion and scorpion was found to have its own fixed plane of movement with respect to the animal's body axis. This is similar to observations made in case of cockroach (NickLAUS, 1965) and one other scorpion species (HofFMAN, 1967). The pattern of cuticular articulation of the hair in its socket gives the hair its specificity in its directional characteristics as discussed by HoFFMAN (1967) and TAUTZ (1979). In case of both whip scorpion and scorpion, the trichobotria are eccentrically placed within their sockets which causes the hair shaft to move to a greater extent in one direction till it is held back by the rim of the socket, and less so in the opposite direction. According to GuTHRIE (1964), the form and physical properties of the hair shaft and its socket are probably more important in determining the directional sensitivity than the asymmetries of the neurons and associated cells.

All the trichobothria of the whip scorpion and scorpion have smooth hair shafts in contrast to feathered hair shafts in spiders (BARTH, 1982).

While the whip scorpion was found to possess only 10 trichobothria, the scorpion was found to be equipped with 96 trichobothria. In spite of the reduced number of wind-sensitive hairs, the whip scorpion was found to be extremely sensitive to air currents to which the animal instantly responds by directing its first legs and whip towards the source of air puffs. However, while the whip scorpion shows such a response to air puffs delivered to it about $60 \mathrm{~cm}$ away (Moro \& GeETHABALI, 1985), the scorpion shows a relatively delayed and weak withdrawal reaction of its pedipalps to air puffs of similar magnitude delivered to it at just $15 \mathrm{~cm}$ away. Thus, whip scorpions seem to be relatively more 
responsive to air currents than scorpions in spite of the small number of trichobothria it possesses.

Generally, trichobothria occur in large numbers in other arachnids, eg., spiders (BARTH, 1982). The filiform thread hairs of insects, which are comparable to trichobothria, are also densely arranged. For example, the adult cockroach has about 220 such hairs on each anal cercus, responding to air puffs (Pumphrey \& RaWdon-Smith, 1936; Nicklaus, 1965). However, the first instar nymphs of cockroach possess only two filiform hairs on each cercus, in spite of which, the nymph's accuracy of turning during escape behaviour was found to be no less than that of an adult (DAGAN \& Volman, 1982). This adds to the view that a reduction in the number of hairs sensitive to air currents does not necessarily reduce the animal's ability to respond accurately to air-borne vibrations.

While all the trichobothria in scorpion are concentrated at the anterior end on the pedipalps, the arrangement of trichobothria on the legs of whip scorpion roughly forms a circle with its axis at the centre of the antero-posterior axis of the animal. Such an arrangement of trichobothria could be best suited in enabling the whip scorpion to perceive air currents equally from all directions with respect to the mid-axis of its body as discussed earlier (MORO \& GEETHABALI, 1985). This fact, combined with the one that trichobothria in the whip scorpion have specific directional mobilities roughly covering $360^{\circ}$ around the animal's centre appears to be responsible in rendering the animal highly sensitive to air-borne vibrations in spite of the meagre number of trichobothria.

\section{Acknowledgements}

A fellowship grant to S.D. Moro from the Department of Atomic Energy, Government of India, and Career Award grant from University Grants Commission to GeETHABALI are gratefully acknowledged.

\section{Literature}

BARth, F.G., 1982. Spiders and Vibratory Signals. Sensory Reception and Behavioural Significance. In: P. N. WiTt and J. Rovner (eds) : Spider Communication. Mechanisms and Ecological Significance. Princeton Univ. Press, Princeton, 67-122.

Christian, U., 1971. Zur Feinstruktur der Trichobothrien der Winkelspinne Tegenaria derhami Scopol (Agelenidae, Araneae). Cytobiol., 4 : 172-185. 
1972. Trichobothrien, ein Mechanorezeptor bei Spinnen. Elektronmikroskopische Befunde bei der Winkelspinne Tegenaria derhami (Scopoli). Verh. dtsch. Zool. Ges., 66: $31-36$.

Dagan, D. \& S. Volman, 1982. Sensory basis for directional wind detection in first instar cockroaches, Periplanata americana. J. comp. Physiol., 147: 471-478.

DAHL, T., 1883. Über die Hörhaare bei den Arachnoiden. Zool. Anz., 6: 267-270.

Emerit, M. \& D.C. Bonaric, 1975. Contribution a'l'étude du developpement de l'appareil, mechanorécepteur des Araignees: la trichobothriotaxie de Pisaura mirabilis $\mathrm{C}_{L}$. (Araneae-Pisauridae). Zool. Jb. Anat., $94: 358-374$.

Gabbut, P.D., 1972. Differences in the disposition of trichobothria in the Chernetidae (Pseudoscorpiones). J. Zool., Lond., 167: 1-13.

Gabbut, P.D. \& M. VAcion, 1965. The external morphology and life history of the pseudoscorpion Neobisium muscorum. Proc. Zool. Soc. Lond., 145: 335-358.

Görner, P., 1965. A proposed transducing mechanism for a multiply-innervated mechanoreceptor (trichobothrium) in spiders. Cold Spr. Harb. Symp. Quant. Biol., 30: 6973.

Görner, P. \& P. Andrews, 1969. Trichobothrien, ein Ferntastsinnesorgane bei Webspinnen (Araneen). Z. vergl. Physiol., 64: 301-331.

GuThRIE, D. M., 1964. Observations on the nervous system of the flight apparatus in the locust Schistocerca gregaria. Quart. J. Microsc. Sci., 105: 183-201.

HARRIS, D. J. \& P.J. Mill, 1977. Observations on the leg receptors of Ciniflo (Araneida, Dictynidae). I. External mechanoreceptors. J. comp. Physiol., 119: 37-54.

Hoffman, C., 1967. Bau und Funktion der Trichobothrien von Euscorpius carpathicus L. Z. vergl. Physiol., 54 : 290-352.

Ignatjev, A. M., V.P. Ivanov \& Y.S. BAlashow, 1976. Fine structure and function of trichobothria in scorpion Buthes eupes Koch (Scorpiones, Buthidae). Rev. d'Entomol. URSS., 3 : 525-532.

Moro, S.D. \& Geetiabali, 1985. The role of trichobothria of whip scorpion in wind perception. Proc. VI All India Symposium on Life Sciences, Tirupathi, 1985: 67-72.

Nicklaus, R., 1965. Die Erregung einzelner Fadenhaare von Periplanata americana in Abhängigkeit von der Grosse und Richtung der Auslenkung. Z. vergl. Physiol., 50 : 331-362.

Pumphrey, R.J. \& A.F. Rawdon-Smith, 1936. Hearing in insects: The nature of the response of certain receptors to auditory stimuli. Proc. Roy. Soc. Lond. B, 121: 18-27.

REIßLAND, A., 1978. Electrophysiology of trichobothria in orb-weaving spiders (Agelenidae, Araneae). J. comp. Physiol., 123: 71-84.

Reißland, A. \& P. Görner, 1978. Mechanics of trichobothria in orb-weaving spiders (Agelenidae, Araneae). J. comp. Physiol., 123: 71-84.

TAutz, J., 1979. Reception of particle oscillation in a medium-an unorthodox sensory capacity. Naturwiss., 66: 452-461.

Weygoldt, P., 1970. Lebenßzyklus und postembryonale Entwicklung der Geißelspinne 
Tarantula marginemaculata C. L. Koch (Chelicerata, Amblypygi) in Laboratorium. Z. Morph. Tiere, 67: 58-85.

Yoshikura, M., 1965. Postembryonic development of a whip scorpion Typopeltis stimpsonii Wood. Kum. J. Sci., Ser. B, Sec. 2: 21-50. 